\title{
Exercises for Treatment of Nonspecific Low Back Pain
}

\author{
Daniele Tatiane Lizier ${ }^{1}$, Marcelo Vaz Perez, TSA ${ }^{2}$, Rioko Kimiko Sakata, TSA ${ }^{3}$
}

Summary: Lizier DT, Perez MV, Sakata RK - Exercises for Nonspecific Low Back Pain Treatment.

Background and objectives: Low back pain is a common syndrome that causes disability and absence from work. Although there are several causes, the most common type of back pain is nonspecific. Exercises are often used to treat back pain, but there is controversy regarding its effectiveness. The aim of this paper is to review exercises for nonspecific low back pain treatment.

Content: This paper provides a definition and classification of back pain. Incidence and mechanisms of nonspecific low back pain and exercises used for its treatment are hereby reported.

Conclusion: The most effective types of exercise therapy for chronic or acute low back pain are still controversial; however, exercise therapy is probably the most widely used conservative treatment throughout the world.

Keywords: Exercise; Low Back Pain; Muscle Stretching Exercises.

\section{INTRODUCTION}

Low back pain (LBP) is one of the most frequent causes of disability. LBP is usually defined as pain localized below the margin of the last ribs (costal margin) and above the inferior gluteal lines, with or without lower limb pain ${ }^{3}$. It has a prevalence of $60-85 \%$ during an individual's lifetime ${ }^{1}$. At some point in life, between $15 \%$ and $20 \%$ of adults have this syndrome ${ }^{1,2}$. Most cases $(90 \%)$ are nonspecific and occur in all age groups ${ }^{1}$. Local sources of LBP are intervertebral discs, facet joints, sacroiliac joints, muscles, fascia, bones, nerves, and meninges ${ }^{4}$. Causes of LBP are herniated discs, osteoarthritis, myofascial syndrome, spondylolisthesis, ankylosing spondylitis, rheumatoid arthritis, fibrosis, arachnoiditis, tumor, and infection. The number of spinal disorders is large, particularly those related to posture, inadequate body movements, and working conditions that may affect the spine ${ }^{5}$. Due to the variety of factors involved, no therapeutic technique is effective for all patients.

\footnotetext{
Received from the Department of Anesthesiology, Pain, and Intensive Care, Universidade Federal de São Paulo (Unifesp).

1. Physical Therapist, Universidade Federal de São Paulo (Unifesp)
2. PhD; Staff Anesthesiologist, Unifesp

3. Associate Professor, Head of the Department of Pain, Unifesp

Submitted on November 3, 2011.

Approved on December 9, 2011.

Correspondence to:

Dra. Rioko Kimiko Sakata

R. Três de Maio 61/51

Vila Clementino

04044-020 - São Paulo, SP, Brasil

E-mail: riokoks.dcir@epm.br
}

\section{Classification}

LBP may be classified as mechanical, non-mechanical, and psychogenic. Mechanical LPB may be specific or nonspecific. According to its duration, LBP may be acute (sudden onset and lasting less than six weeks), subacute (lasting 6 to 12 weeks), chronic (lasting longer than 12 weeks), and recurrent (reappears after lull periods) ${ }^{6}$. It can be divided into five categories: viscerogenic (e.g. abdominal diseases), vascular (e.g. abdominal aortic aneurysm), psychogenic (psychological factor inducing pain), neurogenic (nervous system injury), and espondylogenic (e.g. disc herniation and osteoarthritis) ${ }^{7}$. LBP caused by musculoskeletal disorder can be congenital, degenerative, inflammatory, infectious, malignant, and mechanical postural.

\section{Nonspecific low back pain}

Mechanical - or nonspecific - LBP is the most commonly reported by the population. The human body has a center of gravity, which keeps the balance between muscles and bones to maintain the integrity of structures and protect them against injury, in any position - standing, sitting or laying down. In nonspecific LBP, imbalance typically occurs between the functional load - which is the effort required for work and activities of daily living, and ability - which is the potential for performing these activities. Nonspecific LBP is characterized by the absence of structural change; that is, there is no disc space reduction, nerve root compression, bone or joint injuries, marked scoliosis or lordosis that may lead to back pain. Only $10 \%$ of LBP has a specific cause due to a particular disease ${ }^{8}$. Despite 
the lack of structural change in nonspecific LBP, it can limit daily activities and cause temporary or permanent inability to work, being one of the main causes of absence at work in the Western world ${ }^{1}$.

The incidence of nonspecific LBP is higher in workers subjected to heavy physical exertion, such as weight lifting, repetitive movements, and frequent static postures ${ }^{9,10}$.

In literature, the nonspecific LBP prevalence is higher in females ${ }^{11,12,13}$. Some authors believe that the risks are higher in women than in men because of anatomical and functional peculiarities that, combined, may facilitate the emergence of low back pain. Women have lower height, less muscle mass and bone density, greater joint fragility, and lower adaptation to physical exertion ${ }^{14}$. Furthermore, the sum of the burden imposed by housekeeping increases this risk ${ }^{15}$. Therefore, almost all individuals have episodes of nonspecific LBP, and all age groups are considered at risk.

Habitual or professional postures (remaining in a standing or sitting position for long periods of time), obesity, pendulous abdomen, visceroptosis, vicious foot, and muscle masses not sufficiently developed are all contributing factors to postural distortions. Excess weight produces greater pressure on structures (intervertebral discs, nerve roots, interapophyseal joints, and interspinous ligaments) and cause pain. Other factors contributing to LBP in obese patients are flaccidity and abdominal wall distention, which prevents proper spinal support ${ }^{16,17}$. Nonspecific LBP is caused by postural deviations.

The characteristics of nonspecific LPB are heavy pain, worsening with exertion especially in the afternoon, relieved with rest, absence of neurological and muscle contraction, and antalgic posture, associated with inactivity and poor posture ${ }^{18}$.

Several factors are associated with LBP and affect its development and, subsequently, its course. In a systematic review, the authors concluded that none of the abnormalities identified by magnetic resonance imaging - such as reduction of disk space, degeneration or even herniated disc - was related to the cause of LBP, as these abnormalities were also present in asymptomatic individuals and did not coincide with the development of LBP 19,20.

\section{Treatments for LBP}

There are several treatments for LBP, such as medications (anti-inflammatories, corticosteroids, paracetamol, dipyrone, tramadol, opioids, muscle relaxants, antidepressants, anticonvulsants), physical measures (short waves, ultrasound, transcutaneous electrical stimulation, laser), infiltration, blockade, and acupuncture. However, the effectiveness of the therapeutic interventions is not fully proven $4,21,22,23,24$.

\section{Exercise}

Exercise therapy comprises a heterogeneous group of interventions. Exercise for LBP can be done individually for each group of patients, under the supervision of a therapist, or at home. They can be performed using exercise machines or in the pool. Various types of exercises, such as aerobics, flexion or extension, stretching, stabilization, balance and coordination, are used. For muscle strengthening exercises, attention can be given to a specific muscle (multifidus, transversus abdominis) or a group of muscles, such as the torso and abdomen. Exercises may vary in intensity, frequency, and duration.

Among the various reviews found, two can be highlighted ${ }^{25,26}$. In the first, the authors found 37 studies that met the inclusion criteria. Of these, nine were revisions of exercises, with eight showing some evidence of exercise effect on LBP. However, the sample size was small. Only one review with a considerable size sample showed evidence that general exercise improves LBP and, consequently, absence from work. Exercise reduces LBP intensity and helps the patient's recovery, but does not prevent recurrence ${ }^{25}$. In the second systematic review, when looking for the best method of intervention and rehabilitation for LBP, the authors investigated exercises, back schools, transcutaneous electrical stimulation, low-level laser, education, massage, behavioral therapy, traction, multidisciplinary treatments, and thermotherapy ${ }^{26}$. Eighty-three randomized double-blind trials were found, most of which was of therapeutic exercises (37) and behavioral therapy (21). The conclusion was that therapeutic exercises promote reduction of pain intensity and disability for a long period, whereas cognitive behavioral therapy is more effective in reducing pain intensity for short periods; however, the level of evidence is still low. For other methods, due to the heterogeneity of the study population, intervention, and groups, it was impossible to reach a conclusion.

Therapeutic exercises are defined as a set of specific movements with the objective of developing and training the muscle and joints with the use of a practice routine or physical training in order to promote the physical health of the individual ${ }^{27}$.

In one study, the authors demonstrated the greater efficacy of specific exercises for transversus abdominis compared with general exercise and spinal manipulative therapy in patients with LBP. The effect of motor control exercise on pain reduction was greater compared with other groups. There was also a significant correlation between moderate recruitment of transversus abdominis and decreased disability, which once again demonstrates the importance of this muscle action on lumbar spine stability ${ }^{28}$.

In another study of a six-week program of segmental stabilization exercises for individuals with chronic LBP, it was possible to see significant differences between treatment and control groups in quality of life questionnaire. There was significant reduction of pain and disability in the group of subjects studied, and $89 \%$ of patients considered their pain intensity and functional disability acceptable ${ }^{29}$.

Specific exercises promoting contraction independent of the deep trunk muscles, with transversus abdominis and multifidus contraction, is beneficial for reducing pain and disability in patients with chronic LBP, in addition to recurrence after an episode of acute pain ${ }^{30}$.

The effectiveness of rehabilitation through active exercise has been documented in randomized controlled trials. In patients with nonspecific LBP, a program of active mobilization 
was compared with passive mobilization. There was a greater reduction in pain intensity in the group of active rehabilitation. After one year, the difference in pain intensity and disability index was even more significant. Change in lumbar strength was significantly higher in active rehabilitation group than in the control group (passive treatment) ${ }^{31}$.

In one study, 235 nurses who had at least one episode of LBP were invited and 169 of them were qualified. The general exercise program consisted of 11 sessions of 1-hour each, and included muscle strengthening and stretching exercises, as well as guidelines for a training program at home. The secondary prevention program consisted of 17 sessions of 1-hour and 35 minutes and an individual session of 45 minutes. In addition to the exercise program, the prevention program included a psychological program, segmental stabilization exercises, and ergonomics. The multimodal program was not superior to the general exercise program with stretching and strengthening for improvement of LBP. Considering the lower cost of the general exercise program, a multimodal program for secondary prevention of nonspecific LBP and disability is not justified ${ }^{32}$.

Back school is defined as a postural education program used for the prevention and treatment of patients with LBP, which includes therapeutic exercises and theoretical and practical lessons given to a group of patients, supervised by a physical therapist or medical specialist ${ }^{33}$.

Cognitive behavioral therapy involves relaxation and cognitive techniques, social training, and acceptance and adaptation of activities to improve pain and functional capacity ${ }^{34,35}$. In this review, we found 11 studies comparing interventional exercises. However, due to the great heterogeneity of intervention and exercises, duration of exercises, and time of each session, as well as the follow-up time, it was impossible to reach a conclusion.

In two studies, the authors found differences between therapeutic exercises. In one study, the aerobic exercise program promoted greater pain relief after a three-month follow-up ${ }^{36}$. In another study, the stretching and strengthening exercise program was compared with the motor exercise program over 12 weeks. The motor exercise program group had little improvement in results after eight weeks; however, in the 6 to 12 months follow-up there was no difference in results ${ }^{37}$.

In eight studies, the authors found no difference between the various types of therapeutic exercises ${ }^{38,39}$. The authors performed a systematic review of exercise and LBP and found 28 citations in English, which included 23 randomized controlled trials published between 1993 and 2004 and five literature reviews published in 2000 and 2002. In earlier studies, there is no support for acute LBP exercises, but for chronic LBP. Recent studies have classified treatment based on function and not duration, taking into account patient preference and working with muscle groups that increase stabilization. There are benefits lasting up to three years after the intervention ${ }^{40}$. Identification of the specific functional characteristics of each individual enables professionals to design therapies focused on LBP 25.
There is still uncertainty about the most effective approach to exercise for LBP. A systematic review was conducted to identify the characteristics of each exercise to decrease the intensity of pain and improve function in patients with nonspecific LBP. Stretching and strengthening exercises were more effective compared with other types of therapies. However, some limitations were found in the literature, including lowquality with different outcome measures as well as inconsistent and poor reporting. Exercise therapy for individual programs, including stretching or strengthening with supervision, may improve pain and function in nonspecific LBP. Strategies should be used to encourage adherence. Future studies should test this model and assess the characteristics and types of exercises for each patient ${ }^{41}$.

Treatment guidelines in the United Kingdom were based on moderate degree of clinical research evidence, clinical trials, and systematic reviews. The treatment aims to maintain the highest level of activity possible. Medication should be used to decrease pain intensity; however this orientation may not yield results in some patients. The guidelines consist of structured exercise programs with the supervision of a licensed professional, such as a physiotherapist. Exercises are done in a maximum of eight supervised sessions in a period of 8 to 12 weeks, in groups, and include aerobic activity, direction of movement, muscle stretching, postural control, and spine rectification. The patient is encouraged and recommended to exercise alone at home daily in addition to manual therapy, which includes several sessions of massage, spinal mobilization or manipulation. When mobilizing, the therapist moves the joints of the vertebral column within the normal range of movement. In manipulation, the therapist moves the spinal column joints beyond the normal range of motion. Acupuncture is recommended, although the level of evidence is very low. The guidelines also include cognitive behavioral therapy. Finally, if not all the above steps work, the National Institute for Clinical Excellence (NICE) recommends that general practitioners refer patients to a clinical pain specialist. Spinal surgery is rarely recommended when all types of treatment had no effect and the pain is still severe ${ }^{42}$.

Interaction and communication among the various health professionals, i.e., the interdisciplinary and multidisciplinary approach, may help patients with chronic nonspecific LBP. This includes not only physical exercises, but other modalities of pain treatment mentioned above.

\section{CONCLUSION}

Studies of the most effective types of exercise therapy for chronic or acute LBP are still controversial in literature; however, therapeutic exercises are probably the most widely used conservative treatment. Exercise standardization, as well as duration, frequency and time of evaluation are necessary to reduce the risk of misinterpretation in determining the most appropriate modality for a given population affected by nonspecific LBP. Exercises that are done incorrectly can 
be harmful to their health. The most obvious examples are weight exercises in the sitting position and front and side load elevations with arms outstretched. Performed with a wrong posture or excess weight, exercises can cause shoulder and back pain. To keep the body in shape without hurting oneself, exercise that is not harmful to the joints or tendons should be done. The guidelines above which focused on each patient's needs by a properly trained professional with knowledge of biomechanics are meant to avoid physical activity interruption, which is of great importance to physical and mental health. 


\section{REFERENCES}

1. Krismer $\mathrm{M}$, van Tulder $\mathrm{M}$ - Strategies for prevention and management of musculoskeletal conditions. Low back pain (non-specific). Best Pract Res Clin Rheumatol, 2007;21:77-91.

2. Fernández-de-las-Peñas $C$, Hernández-Barrera $V$, Alonso-Blanco $C$ et al. - Prevalence of neck and low back pain in community-dwelling adults in Spain: a population-based national study. Spine (Phila $\mathrm{Pa}$ 1976), 2011;36(3):E213-9.

3. Van Middelkoop M, Rubinstein SM, Verhagen AP et al. - Exercise therapy for chronic nonspecific low-back pain. Best Pract Res Clin Rheumatol, 2010;24(2):193-204.

4. Winkelstein BA, Weinstein JN, DeLeo JA - The role of mechanical deformation in lumbar radiculopathy: an in vivo model. Spine (Phila Pa 1976), 2002;27(1):27-33.

5. Verbeek JH, van der Weide WE, van Dijk FJ - Early occupational health management of patients with back pain: a randomized controlled trial. Spine (Phila Pa 1976), 2002;27(17):1844-1851.

6. Bratton $\mathrm{RL}$ - Assessment and management of acute low back pain. Am Fam Physician, 1999 Nov 15;60(8):2299-308.

7. Stanton TR, Latimer J, Maher CG et al. - How do we define the condition 'recurrent low back pain'? A systematic review. Eur Spine J, 2010;19:533-539.

8. Deyo RA, Rainville J, Kent DL - What can the history and physical examination tell us about low back pain? Jama, 1992;268(6):760-765.

9. Andrade SC, Araújo AG, Vilar MJ - Escola de Coluna: revisão histórica e sua aplicação na lombalgia crônica. Rev Bras Reumatol, 2005;45(4):224-248.

10. Dagenais S, Caro J, Haldeman S - A systematic review of low back pain cost of illness studies in the United States and internationally. Spine J, 2008;8(1):8-20.

11. Smith SJ, Keefe FJ, Caldwell DS et al. - Gender differences in patientspouse interactions: a sequential analysis of behavioral interactions in patients having osteoarthritic knee pain. Pain, 2004;112(1-2):183187.

12. Schneider S, Randoll D, Buchner M - Why do women have back pain more than men? A representative prevalence study in the federal republic of Germany. Clin J Pain, 2006;22(8):738-747.

13. Cecchi F, Debolini P, Lova RM et al. - Epidemiology of back pain in a representative cohort of Italian persons 65 years of age and older: the InCHIANTI study. Spine (Phila Pa 1976), 2006;31(10):1149-1155.

14. Bassols A, Bosch F, Campillo M et al. - Back pain in the general population of Catalonia (Spain). Prevalence, characteristics and therapeutic behavior. Gac Sanit, 2003;17(2):97-107.

15. Silva MC, Fassa AG, Valle NC - Chronic low back pain in a Southern Brazilian adult population: prevalence and associated factors. Cad Saude Publica. 2004;20(2):377-385.

16. Muehlbacher M, Nickel MK, Kettler $\mathrm{C}$ et al. - Topiramate in treatment of patients with chronic low back pain: a randomized, double-blind, placebo-controlled study. Clin J Pain, 2006;22(6):526-531.

17. Heuch I, Hagen K, Heuch I et al. - The impact of body mass index on the prevalence of low back pain: the HUNT study. Spine (Phila Pa 1976), 2010;35(7):764-768.

18. Meleger AL, Krivickas LS - Neck and back pain: musculoskeletal disorders. Neurol Clin, 2007;25(2):419-438.

19. Cheung KM, Karppinen J, Chan D et al. - Prevalence and pattern of lumbar magnetic resonance imaging changes in a population study of one thousand forty-three individuals. Spine, 2009;34:934-940.

20. Endean A, Palmer KT, Coggon D - Potential of magnetic resonance imaging findings to refine case definition for mechanical low back pain in epidemiological tudies: a systematic review. Spine, 2011;36:160169.

21. Chou R - Pharmacological management of low back pain. Drugs, 2010;70:387-402.

22. Keller $\mathrm{K}$ - Exercise therapy for low back pain: a narrative review of the literature. J Chiropr Med, 2006;5(1):38-42.

23. Huntoon MAS, Burgher $\mathrm{AH}-\mathrm{Back}$ to the future: the end of the steroid century?. Pain Physician, 2008;11:713-716. 
24. Artus M, van der Windt DA, Jordan KP et al. - Low back pain symptoms show a similar pattern of improvement following a wide range of primary care treatments: a systematic review of randomized clinical trials. Rheumatology (Oxford), 2010;49:2346-2356.

25. Van Middelkoop M, Rubinstein SM, Verhagen AP et al. - Exercise therapy for chronic nonspecific low-back pain. Best Practice Res Clin Rheumatol, 2010;24:193-204.

26. Kuijpers T, van Middelkoop M, Rubinstein SM et al. - A systematic review on the effectiveness of pharmacological interventions for chronic non-specific low-back pain. Eur Spine J, 2011;20(1):40-50.

27. Abenhaim L, Rossignol M, Valat JP et al. - The role of activity in the therapeutic management of back pain. Report of the International Paris task force on back pain. Spine, 2000;25:1S-33S.

28. Ferreira $P$, Ferreira $M$, Maher $C$ et al. - Changes in recruitment of transversus abdominis correlate with disability in people with chronic low back pain. Br J Sports Med, 2010:605-614.

29. Norris $C$, Matthews $M$ - The role of an integrated back stability program in patients with chronic low back pain. Complement Ther Clin Pract, 2008;14(4):255-263.

30. Van Tulder M, Malmivaara A, Esmail R et al. - Exercise therapy for low back pain: a systematic review within the framework of the Cochrane collaboration back review group. Spine, 2000;25(21):2784-2796.

31. Kankaanpää $M$, Taimela $S$, Airaksinen $O$ et al. - The efficacy of active rehabilitation in chronic low back pain. Effect on pain intensity, selfexperienced disability, and lumbar fatigability. Spine (Phila Pa 1976), 1999;24(10):1034-1042.

32. Ewert $\mathrm{T}$, Limm H, Wessels $\mathrm{T}$ et al. - The comparative effectiveness of a multimodal program versus exercise alone for the secondary prevention of chronic low back pain and disability. PM R, 2009;1(9):798808.

33. Heymans MW, van Tulder MW et al. - Back schools for non-specific low-back pain. Spine (Phila Pa 1976), 2005;30:2153-2163.

34. Ostelo RW, van Tulder MW, Vlaeyen JW et al. - Behavioural treatment for chronic low-back pain. 2005 Cochrane Database Syst Rev:CD002014

35. Rainville J, Nguyen R, Suri P - Effective conservative treatment for chronic low back pain. Semin Spine Surg 2009;21(4):257-63.

36. Tritilanunt $\mathrm{T}$, Wajanavisit $\mathrm{W}-$ The efficacy of an aerobic exercise and health education program for treatment of chronic low back pain. $J$ Med Assoc Thai, 2001;84(Suppl 2):S528-S533.
37. Ferreira ML, Ferreira PH, Latimer J - Comparison of general exercise, motor control exercise and spinal manipulative therapy for chronic low back pain: a randomized trial. Pain, 2007;131:31-37.

38. Yozbatiran N, Yildirim Y, Parlak B - Effects of fitness and aquafitness exercises on physical fitness in patients with chronic low back pain. Pain Clinic, 2004;16:35-42.

39. Harts CC, Helmhout PH, Bie RA et al. - A high-intensity lumbar extensor strengthening program is little better than a low-intensity program or a waiting list control group for chronic low back pain: a randomised clinical trial. Aust J Physiother, 2008;54:23-31.

40. Keller A, Hayden J, Bombardier C - Effect sizes of non-surgical treatments of non-specific low back pain. Eur Spine J, 2007;16:17761788.

41. Hayden JA, van Tulder MW, Tomlinson G - Systematic review: strategies for usingexercise therapy to improve outcomes in chronic low back pain. Ann Intern Med, 2005;142(9):776-785.

42. Nice - http://www.nice.org.uk/nicemedia/live/11887/44334/44334.pdf acessado em 21/09/2011. 